\title{
Donor Cellular Infusion
}

National Cancer Institute

\section{Source}

National Cancer Institute. Donor Cellular Infusion. NCI Thesaurus. Code C77273.

A form of adoptive immunotherapy used after hematopoietic stem cell transplantation

(HSCT ). Lymphocytes from the original stem cell donor are given to the HSCT recipient, after the transplant, to augment an antitumor immune response (graft-versus-tumor), or ensure that the donor stem cells remain engrafted. Although lymphocytes are the most commonly used cell, other cells including fibroblasts, mesenchymal or dendritic cells may be delivered to affect chimerism, treat Graft vs. Host Disease, treat viral infections or Post Transplant Lymphoproliferative Disease or other novel uses under investigation. 